\title{
COMENTARIO A LA SENTENCIA DEL TRIBUNAL CONSTITUCIONAL, SOBRE REQUERIMIENTO DE INAPLICABILIDAD POR INCONSTITUCIONALIDAD DEL ART. 5, INCISO SEGUNDO Y ART. 21, No 1, LETRA B, DE LA LEY No 20.285. DICTADA CON FECHA 05 DE JUNIO DE 2012, EN CAUSA ROL No 1.990-11
}

\author{
FranCISCO ZÚNIGA URBINA \\ Profesor titular de Derecho Constitucional \\ Universidad de Chile
}

\section{REQUERIMIENTO}

El requerimiento dice relación con una solicitud de información, bajo la normativa de lo dispuesto en la Ley No 20.285, realizada a la Dirección Nacional de Servicio Civil, relativa al proceso de selección del Director Nacional del Fondo de Solidaridad e Inversión Social (FOSIS).

$\mathrm{Al}$ efecto, el requirente de autos se opuso a la solicitud de información, puesto que consideró que la misma afectaba los principios de confidencialidad y reserva que regían el proceso de selección en el que participó.

El Consejo para la Transparencia estimó que la Dirección Nacional de Servicio Civil debía entregar toda la información que le había sido requerida, con la sola excepción de las referencias que se hagan a terceros.

El requirente estima que las disposiciones impugnadas vulneran su derecho a la intimidad, consagrado en el Art. 19 No 4 de la Constitución, ya que hace públicos antecedentes que le afectan directamente, y que la propia Ley No 19.882 , que regula los procesos de selección para la alta dirección pública señala que tiene el carácter de confidencial.

Se solicita entonces la inaplicación del Art. $5^{\circ}$ de la Ley No 20.285, ya que ella dispone que es pública toda información que se encuentre en poder de la Administración y haya sido elaborada con fondos públicos. Y se solicita la inaplicabilidad del Art. 21, No 1 letra b, de la misma ley, por cuanto ahí se dispone que los antecedentes del proceso de selección son públicos una vez finalizados éstos. 


\section{Conflicto Constitucional}

En sus dos primeros considerandos, la sentencia enmarca el conflicto constitucional sometido a su decisión, señalando:

"Primero: Que en el caso de autos se impugna los artículos 5०, inciso segundo, y 21 No 1, letra b), de la Ley No 20.285, sobre Acceso a la Información Pública, disposiciones que pueden resultar decisivas para la resolución del asunto.

El texto de la primera de las normas individualizadas precedentemente reza de la manera que sigue:

Articulo $5^{\circ}$. En virtud del principio de transparencia de la función pública, los actos y resoluciones de los órganos de la Administración del Estado, sus fundamentos, los documentos que les sirvan de sustento o complemento directo y esencial, y los procedimientos que se utilicen para su dictación, son públicos, salvo las excepciones que establece esta ley y las previstas en otras leyes de quórum calificado.

Asimismo, es pública la información elaborada con presupuesto público y toda otra información que obre en poder de los órganos de la Administración, cualquiera sea su formato, soporte, fecha de creación, origen, clasificación o procesamiento, a menos que esté sujeta a las excepciones señaladas.

La segunda de las normas impugnadas dispone que:

Artículo 21. Las únicas causales de secreto o reserva en cuya virtud se podrá denegar total o parcialmente el acceso a la información, son las siguientes:

1. Cuando su publicidad, comunicación o conocimiento afecte el debido cumplimiento de las funciones del órgano requerido, particularmente:

(...) b) Tratándose de antecedentes o deliberaciones previas a la adopción de una resolución, medida o política, sin perjuicio que los fundamentos de aquéllas sean públicos una vez que sean adoptadas. (...)';

Segundo: Que, según se ha señalado en la parte expositiva de esta sentencia, el requirente pretende la inaplicabilidad de los preceptos reprochados en autos, aduciendo, en síntesis, que las disposiciones impugnadas, al declarar que es pública la información elaborada con presupuesto público y la que obre en poder de los órganos de la Administración del Estado, cualquiera sea el formato en que se contenga, como asimismo al señalar como públicos los fundamentos de una resolución, medida o política, una vez que hayan sido adoptados, vulneran el derecho al respeto y protección de la vida privada del requirente, reconocido en el artículo 19, No $4^{\circ}$, de la Constitución;”.

\section{Cuestiones Previas}

A continuación, la sentencia se ocupa de "cuestiones previas" o preliminares a la decisión, específicamente la posible inadmisibilidad del requerimiento por 
haber sido las normas impugnadas objeto de examen de constitucionalidad anteriormente, ante lo que se señala que en la especie esta disposición no es aplicable:

"Cuarto: Que el artículo 84 de la Ley No 17.997, orgánica constitucional de este Tribunal, en su No 2, señala que procederá declarar la inadmisibilidad de un requerimiento 'cuando la cuestión se promueva respecto de un precepto legal que haya sido declarado conforme a la Constitución por el Tribunal, sea ejerciendo el control preventivo o conociendo de un requerimiento, y se invoque el mismo vicio que fue materia de la sentencia respectiva'. Así, se ha sentenciado la improcedencia de la inaplicabilidad por tratarse de 'el vicio considerado y desechado por la sentencia' (STC 1406/2009). Mientras que, en otro caso, se ha desechado en atención a que 'el objeto de dicho pronunciamiento es, por su naturaleza, distinto al control que esta Magistratura realiza en sede de inaplicabilidad y recae sobre otra parte de la misma disposición legal' (STC 1564/2010);

Quinto: Que, en este caso, no resulta procedente aplicar la causal de inadmisibilidad. Por una parte, porque se trata de un control de carácter concreto. Por la otra, porque se han invocado diversos vicios que no fueron objeto de debate específico en la revisión preventiva de constitucionalidad efectuada por esta Magistratura en los autos Rol No 1051/2008. Esta se hizo teniendo en cuenta únicamente el artículo $8^{\circ}$ de la Constitución;".

\section{Ratio Decidendi}

En su estructura argumentativa la sentencia del Tribunal hace un distingo básico entre cuestiones de mera legalidad y cuestiones de constitucionalidad, verdadero comodín procesal, empleado tanto en los juicios de admisibilidad como en las sentencias de término.

\subsection{Cuestiones de Mera Legalidad}

"Sexto: Que, a continuación, antes de entrar al análisis de la cuestión planteada, es necesario formular una serie de criterios interpretativos que van a guiar nuestro razonamiento.

En primer lugar, como lo ha señalado reiteradamente esta Magistratura, no le corresponde a ella determinar, frente a un conflicto de leyes, cuál corresponde aplicar, materia que es atribución exclusiva del juez de fondo. En efecto, se ha sentenciado que 'son los jueces del fondo, en las instancias pertinentes, los llamados a determinar las normas legales aplicables a la solución del conflicto jurisdiccional sometido a su decisión y, en caso de conflicto de leyes, a aplicar los principios generales de hermenéutica para su solución' (STC 1925/2011). El asunto es particularmente 
relevante, porque existen dos normas en la Ley No 19.882 que dan carácter de 'reservado' (artículo 50) o 'confidencial' (artículo 55) a aspectos de los concursos para altos directivos públicos, que podrían enmarcarse en la causal de reserva de ley que contemplan la Constitución (artículo $8^{\circ}$ ) y el artículo 21 de la Ley No 20.285, como excepciones a la publicidad. Tal juego de normas le corresponde resolverlo al juez del fondo;”.

\subsection{Cuestiones de Constitucionalidad}

En cuanto a las cuestiones de constitucionalidad, en primer lugar, se hace referencia a la forma que debe tomar un conflicto de constitucionalidad en sede de inaplicabilidad que activa un control concreto:

"Séptimo: Que, en segundo lugar, para efectuar el análisis de la impugnación de autos, se debe hacer presente que la confrontación entre la norma legal y la disposición constitucional, que puede dar lugar a la declaración de inaplicabilidad, está referida a la aplicación del precepto legal impugnado a un caso concreto. De ahí que las características y circunstancias de ese caso concreto de que se trate, adquieren relevancia capital, pues de ellas depende que el precepto legal objetado sea aplicable y decisorio en el proceso pendiente, como también que los efectos de la aplicación de una disposición legal puedan contravenir lo dispuesto en la Carta Fundamental.

En efecto, como ha señalado la doctrina, 'la inaplicabilidad cumple la función de impedir que la parte que la invoca en el caso concreto del que conoce un tribunal, se vea afectada por un precepto legal cuya aplicación a ese caso particular resulte evidentemente contraria a la Constitución y, especialmente, a los fines perseguidos por ésta. De alli que en este instituto procesal-además del juez y de las partes-comparecen tres elementos de cotejo necesarios para su decisión, a saber: la norma constitucional, el precepto legal cuya inaplicación se solicita y -lo más especificamente decisivo-el examen particular acerca de si, en ese caso, la aplicación del precepto cuestionado pudiera generar efectos opuestos a la finalidad implícita de aquélla' (Ríos Álvarez, Lautaro; "Trascendencia de la Reforma Constitucional en la Fisonomía y las Atribuciones del Tribunal Constitucional”, Revista Estudios Constitucionales, № 1, 2005, p. 77). Por consiguiente y considerando que la apreciación que se realizará en esta sentencia no dice relación con un juicio abstracto sobre la compatibilidad del precepto impugnado con la Carta Fundamental, sino con el efecto que su aplicación pueda tener en una gestión judicial pendiente, es imperativo atender a las circunstancias que particularizan el reclamo de ilegalidad en el que incidirá el presente pronunciamiento de inaplicabilidad;".

En segundo término, se define la forma en cómo el Tribunal Constitucional debe abordar la solución de conflicto que se le ha planteado: 
"Octavo: Que, en tercer lugar, el Tribunal Constitucional, en ejercicio de su competencia para conocer y resolver las acciones de inaplicabilidad, ha sido llamado a custodiar la supremacía de la Constitución en aras de tutelar la adecuación de la actuación de los órganos del Estado a la esfera de su competencia, la dignidad de la persona humana y los derechos fundamentales. Es por ello que, en este examen de constitucionalidad, no puede limitarse a confrontar el precepto impugnado con las disposiciones fundamentales que estatuyen las funciones de los distintos órganos, sino que además, y de manera imperativa, debe examinar si la aplicación del precepto legal puede vulnerar los derechos que el orden supremo garantiza y que el actor pretende conculcados en la gestión judicial pendiente (STC 1380/2009);”.

Finalmente, se refiere la sentencia a la relación que debe existir entre la Constitución y la ley para efectos interpretativos:

"Noveno: Que, finalmente, este Tribunal debe interpretar la Constitución para tomar una decisión. Para ello, puede tomar como punto de partida la normativa legal vigente en la materia. Pero no puede interpretar la Constitución como si las regulaciones legales fueran las que fijaran su sentido y alcance. Son las leyes las que deben interpretarse conforme a la Constitución, y no ésta en base a las leyes. Específicamente, no es la Constitución la que debe interpretarse a la luz de la Ley No 20.285, sino ésta por aquélla;".

\subsection{Antecedentes}

Luego, la sentencia examina los antecedentes del conflicto sometido a su decisión. En este sentido, expone el fundamento constitucional del mecanismo de selección de altos directivos públicos:

"Decimotercero: Que este mecanismo de selección de los altos directivos públicos tiene distintos fundamentos constitucionales. Por de pronto, el que la Constitución establezca que la admisión a las funciones y empleos públicos se hará sin otros requisitos que los que impongan la misma Constitución y las leyes (artículo 19, No 17). Enseguida, de acuerdo al artículo 32, No 10, de la Constitución, el Presidente de la República tiene la facultad especial de 'nombrar y remover a los funcionarios que la ley denomina como de su exclusiva confianza'. Finalmente, el artículo 38 de la Constitución, que establece que la Ley Orgánica de la Administración del Estado debe garantizar 'los principios de carácter técnico y profesional en que deba fundarse' y 'la igualdad de oportunidades de ingreso a ella' (artículo 38);".

Posteriormente, se expone el contenido de la decisión dictada por el Consejo para la Transparencia: 
"Decimoquinto: Que, enseguida, lo que la resolución del Consejo para la Transparencia ha ordenado entregar es la evaluación personal del recurrente, elaborada a propósito del concurso desarrollado por la Dirección Nacional del Servicio Civil. Esta incluye la evaluación psicológica del mismo, la evaluación de atributos con puntajes, la descripción de la motivación y la conclusión (síntesis de las fortalezas, oportunidades, debilidades y amenazas).

El informe de evaluación personal es, de conformidad al artículo $2^{\circ}$ de la Ley No 19.628, un dato sensible. Por una parte, porque se trata de aquellos datos personales que se refieren a las características físicas o morales de las personas o a hechos o circunstancias de su vida privada o intimidad. Por la otra, porque dicha disposición expresamente señala como ejemplo de estos datos 'los estados de salud físicos o síquicos'. La evaluación personal es parte de la salud psíquica de una persona.

Al tener tal carácter, no pueden ser objeto de tratamiento de datos (artículo 10, Ley No 19.628), por afectar la vida privada de las personas, salvo que la ley lo autorice o su titular consienta en ello;".

\subsection{Art. $8^{\circ}$ de la Constitución}

Ya de lleno en el fondo de lo debatido, la sentencia examina detalladamente el contenido normativo, y las implicancias del Art. $8^{\circ}$ de la Constitución.

\subsubsection{Alcances}

En primer lugar, a este respecto, se examinan los alcances de la norma Constitucional, en primer lugar el contenido y origen de la norma:

"Decimosexto: Que, analizados los dos antecedentes señalados, debemos partir por examinar el artículo $8^{\circ}$ de la Constitución. Éste señala, en su inciso segundo, que 'son públicos los actos y resoluciones de los órganos del Estado, así como sus fundamentos y los procedimientos que utilicen. Sin embargo, sólo una ley de quórum calificado podrá establecer la reserva o secreto de aquéllos o de éstos, cuando la publicidad afectare el debido cumplimiento de las funciones de dichos órganos, los derechos de las personas, la seguridad de la Nación o el interés nacional';

Decimoséptimo: Que la regulación de la publicidad de la actuación de los órganos de la administración del Estado ha sufrido una vertiginosa evolución en su regulación. Hasta 1999, las personas no tenían derecho a solicitar antecedentes a estos órganos que no se fundaran en el derecho de petición (artículo 19, No 14). Con la entrada en vigencia de la Ley No 19.653, en diciembre de 1999, este derecho se consagró legalmente. Dicha regulación legal duró hasta la dictación de la reforma constitucional que incorporó el mencionado artículo $8^{\circ}$ 
a la Constitución, en el año 2005. Tres años después, en el año 2008, se dictó la Ley No 20.285, sobre Acceso a la Información Pública. Luego de dictadas las regulaciones complementarias a esta normativa (D.S. No 13, Minsegpres, 2009, y D.S. No 90, Minsegpres, 2009), tanto la jurisprudencia del Consejo para la Transparencia, órgano creado por dicha ley, como de las Cortes de Apelaciones, conociendo el reclamo de ilegalidad que contempla la referida legislación, ha comenzado a delinear esta regulación;".

Posteriormente, se señala con exactitud, cuáles son los ámbitos que deben entenderse incorporados a la regulación del Art. $8^{\circ}$ de la Carta Fundamental, señalándose:

"Decimoctavo: Que el artículo $8^{\circ}$ de la Constitución establece, en primer lugar, una declaración genérica de publicidad de ciertos aspectos de la actuación de los órganos del Estado. No habla ni de acceso, ni de entrega, ni de transparencia. No los descarta; pero tampoco cierra posibilidad al legislador. Tampoco habla de información;

Decimonoveno: Que, en segundo lugar, tampoco establece, como lo hace el inciso primero respecto de la probidad, un principio de publicidad, ni que los órganos del Estado deban 'dar estricto cumplimiento' a dicha publicidad. Ello no desmerece la relevancia del mandato, ni relaja su cumplimiento. Sin embargo, constituye un elemento de interpretación, frente a otras disposiciones constitucionales que sí establecen una consideración de esta naturaleza;

Vigésimo: Que, en tercer lugar, esta norma se aplica a todos los órganos del Estado, no sólo a los órganos de la Administración del Estado. Por lo tanto, queda comprendida aquí cualquier entidad creada por la Constitución o por la ley que ejerza algún tipo de función pública. Indudablemente, la ley tendrá que considerar la naturaleza propia de cada órgano para definir la publicidad. De hecho, eso es lo que ha efectuado la Ley No 20.285, que ha diferenciado ámbitos de aplicación de acuerdo a cada órgano;

Vigésimo Primero: Que, en cuarto lugar, manda que sean públicas tres dimensiones del actuar de los órganos del Estado, precisando, de partida, que la Constitución no habla de información.

Desde luego, manda que sean públicos 'los actos y resoluciones'. Esta expresión es suficientemente amplia como para comprender, de manera genérica, la forma en que los órganos del Estado expresan su voluntad. No pueden, entonces, interpretarse estas expresiones desde la perspectiva de los órganos de la Administración del Estado, pues caben aquí las leyes. Quedan incluidos, entonces, los actos administrativos, sea que decidan o no. En la expresión 'resoluciones', por su parte, se incluyen no sólo las municipales, las que emanan de los jefes de servicio, los reglamentos regionales. También quedan comprendidas aquí las sentencias. 
Enseguida, son públicos también, dice la Constitución, los fundamentos de esos actos. Es decir, las motivaciones. En algunas ocasiones, éstas forman parte del acto mismo. Así ocurre con las sentencias y con los actos administrativos desfavorables, las resoluciones que resuelven recursos administrativos y las que ponen término a un procedimiento, que por mandato de la ley deben fundarse siempre (Ley No 19.880). En estos casos, la notificación o publicación del acto lleva aparejado su conocimiento. Respecto de los actos y resoluciones que no llevan en sí mismos sus fundamentos, la ley debe procurar que las personas puedan acceder a conocerlos. Por ejemplo, pueden acceder al expediente administrativo, donde constan los informes, dictámenes, pruebas, etc.; o a las discusiones, que constan en actas o grabaciones de algún tipo. Nada dice la Constitución respecto de la oportunidad en que debe hacerse público el fundamento. Este, por tanto, puede conocerse simultáneamente con el acto o con posterioridad; y hacerse público de oficio o a petición de parte interesada. Ello lo tendrá que establecer la ley.

Finalmente, la ley manda que sean públicos los procedimientos que utilizan los órganos del Estado para adoptar sus decisiones. Ello implica acceder a los expedientes, donde constan los trámites por los cuales pasa una decisión;".

Finalmente, para fijar los alcances de la norma constitucional, se refiere la sentencia a las modalidades para hacer pública la información, y al secreto que excepcionalmente tiene lugar en la Administración del Estado:

"Vigésimo Segundo: Que cabe precisar que el carácter público que establece la Constitución, en los tres aspectos señalados, puede lograrse a través de las modalidades que el legislador establezca, sin que exista un único mecanismo. Así, por ejemplo, la Ley No 20.285 reconoce que si la información está permanentemente a la disposición del público, o lo está en medios impresos, tales como libros, compendios, folletos, archivos públicos, así como también en formatos electrónicos disponibles en Internet, se cumple este mandato (artículo 15). También cabe la publicación de un acto o resolución, la entrega de un documento, el acceso a ellos, su difusión por distintos medios, como pueden ser los avisos radiales, las notificaciones. Incluso la publicación puede ser íntegra (por ejemplo, artículo 48, Ley No 19.880), en extracto (por ejemplo, artículo 27, Ley No 18.838; artículo $2^{\circ}$, D.L. No 2.186; artículo 15, Código Tributario), en listado o en nómina (artículos 168 y 169, Código Tributario; artículo 12, D.L. No 3.063); por aviso (artículos 6o y 15 Código Tributario; artículo 43, Ley General de Urbanismo y Construcciones), en página web. Todos esos, son mecanismos destinados a dar publicidad y cumplir con el mandato del artículo $8^{\circ}$;

Vigésimo Tercero: Que, en quinto lugar, la Constitución permite que existan excepciones a esta regla general de publicidad. Dichas excepciones, dado el carácter 
general de la publicidad, no son la regla general. Con todo, estas excepciones sólo pueden fundarse en la reserva o secreto. Para que estas excepciones operen legítimamente, establece dos requisitos. Por una parte, deben establecerse por ley de quórum calificado, no por norma administrativa ni por ley simple. Por la otra, deben fundarse en ciertas causales que la misma Constitución lista. Estas son: afectar el debido cumplimiento de las funciones de los órganos del Estado; afectar los derechos de las personas; afectar la seguridad de la nación; y afectar el interés nacional. Dichas causales las califica el Legislador;

Vigésimo Cuarto: Que, asimismo, cabe señalar que el secreto o reserva puede ser definido de dos maneras por el legislador. En unos casos, directamente puede calificar determinados actos, procedimientos o fundamentos como tales. En otros, establece situaciones que, enmarcadas en la disposición constitucional, deben ser calificadas por la administración.

En un caso, el legislador directamente establece la reserva o el secreto (artículos 21, No 5, 22 y $1^{\circ}$ transitorio del artículo primero de la Ley No 20.285). En los otros, requiere de una mediación de la administración (artículo 21, numerales 1 al 4, del artículo primero de la Ley No 20.285).

Respecto de las que implican una calificación administrativa, el legislador contempló la intervención de un organismo administrativo encargado de resolver los reclamos de denegación de acceso a la información;".

\subsubsection{Derecho Implícito}

Seguidamente, la sentencia se hace cargo de la afirmación relativa a que el derecho de acceso a la información pública encuentra, implícitamente, su fuente en la Constitución, pero en modo alguno es un derecho explícito y, por ende, su configuración es legislativa:

"Vigésimo Quinto: Que, en sexto lugar, no consagra el artículo $8^{\circ}$ un derecho de acceso a la información. Este, como esta Magistratura lo ha señalado, se encuentra reconocido implícitamente en el artículo 19, $\mathrm{N}^{\circ} 12^{\circ}$, de la Constitución (STC 634/2007). Su propósito es, por de pronto, garantizar un régimen republicano democrático, que garantice el control del poder, obligando a las autoridades a responder a la sociedad de sus actos y dar cuenta de ellos. También, promover la responsabilidad de los funcionarios sobre la gestión pública. Y, finalmente, fomentar una mayor participación de las personas en los intereses de la sociedad.

No obstante, la ley puede establecer y desarrollar un derecho de acceso a la información, como lo hizo la Ley No 20.285. Pero puede haber otras normativas, que lo configuren de otra manera;". 


\subsubsection{Fuentes de Reserva o Secreto en la ley}

Posteriormente, la sentencia analiza la extensión de la remisión al legislador que tiene la Constitución en su Art. $8^{\circ}$, especialmente sobre la posibilidad de que la ley establezca información reservada o secreta:

"Vigésimo Sexto: Que, finalmente, no manda el artículo $8^{\circ}$ dictar una regulación complementaria especial, que no sea la dictación de dichas leyes de quórum calificado para establecer las hipótesis de secreto o reserva. La normativa complementaria, como la Ley No 20.285, se dicta teniendo como fundamento otros preceptos constitucionales. Por ejemplo, tratándose de la Administración, ésta se funda en los artículos 38, 63, No 18, y 65, inciso cuarto, No 2 .

El punto es importante, porque no una sino varias leyes pueden establecer excepciones a la publicidad de determinados actos, procedimientos o fundamentos. La Ley No 20.285 no puede considerarse como la única y exclusiva normativa que concentra todo lo referente a la publicidad ordenada por el artículo $8^{\circ}$, inciso segundo, de la Carta Fundamental. De hecho, este mismo cuerpo legal asume la existencia de otras disposiciones (por ejemplo, artículos $5^{\circ}$, inciso primero; 10 , inciso segundo; 11, letras b) y d); 21 , No 5, y 22, del artículo primero de la Ley No 20.285);

Vigésimo Séptimo: Que, como se observa, una de las causales que permite que el legislador declare un acto, una resolución, un fundamento o un procedimiento como secreto o reservado, es la afectación de los derechos de las personas. La publicidad es necesaria para el bien común; pero debe hacerse con pleno respecto a los derechos que el ordenamiento establece (artículo $1^{\circ}$, Constitución).

Es lícito, en consecuencia, que el legislador, invocando o teniendo en cuenta un derecho, establezca excepciones a la publicidad.

Cabe resaltar que la Constitución utiliza la expresión 'afectare', no la de privar, amenazar o perturbar. Con ello, permite que el legislador considere cualquier lesión, alteración o menoscabo, como una razón calificada para establecer la excepción a la publicidad.

La Constitución tampoco utiliza la expresión 'derechos constitucionales'. Habla de 'los derechos de las personas'. Caben aquí, en consecuencia, derechos de rango legal.

La Constitución, de igual modo, no señala cuáles son esos derechos.

Lo relevante es que la publicidad del acto o resolución, o de su fundamento o del procedimiento respectivo, afecte los derechos de las personas. Si la afectación no tiene que ver con la publicidad, sino con el acto mismo, o su fundamento, o el procedimiento que le precedió, estamos frente a otro ámbito, diferente del cubierto por el artículo $8^{\circ}$. 
La publicidad que afecta a los derechos puede provenir de la publicación, de la entrega o del acceso de las personas al acto o resolución, al fundamento o procedimiento respectivo;

Vigésimo Octavo: Que la existencia de derechos como límites a la publicidad es reconocida, por ejemplo, por el artículo $1^{\circ}$ de la Ley No 20.285. Desde luego, porque se establece expresamente como causales para denegar total o parcialmente el acceso a la información, que la publicidad afecte a los derechos de las personas, 'particularmente tratándose de su seguridad, su salud, la esfera de su vida privada o derechos de carácter comercial o económico’ (artículo 21, No 2). Enseguida, porque si se solicita un documento o un antecedente que tiene información que afecte derechos de terceros, la autoridad requerida debe consultar a la persona afectada, quien puede oponerse a la entrega de los documentos. Si se opone, en tiempo y forma, el órgano requerido no puede proporcionar la documentación o antecedente (artículo 20) y la presunción de publicidad del antecedente requerido se rompe, pues el interesado debe acompañar en su reclamo al Consejo para la Transparencia los medios de prueba que acrediten su caso (artículos 11, letra c), y 24, inciso segundo). A continuación, porque principios estructurales del derecho de acceso a la información ante los órganos de la Administración del Estado, como el de la libertad de información, el de apertura o transparencia, el de máxima divulgación, se ven limitados ante la presencia de excepciones o limitaciones que establezcan el secreto o reserva (artículo 11). En el mismo sentido se enmarca el hecho de que durante el reclamo jurisdiccional que regula la Ley No 20.285, por haber otorgado el acceso a la información, se suspende la entrega de la información solicitada, sin que la Corte pueda 'decretar medida alguna que permita el conocimiento o acceso a ella' (artículo 29). Finalmente, porque el Consejo para la Transparencia tiene entre sus tareas velar por la debida reserva de los datos e informaciones que, conforme a la Constitución y a la ley, tengan carácter secreto o reservado (artículo 33, letra j);”.

\subsection{Derecho a la Vida Privada}

Posteriormente, la sentencia caracteriza el derecho a la vida privada, garantizado en la Constitución, y la relación del mismo con la normativa que regula el principio de transparencia en la Administración Pública.

"Trigésimo: Que lo primero que cabe señalar respecto de esta disposición, es que la Constitución asegura 'el respeto y protección'. Con la primera expresión, se alude al deber que tienen todas las personas y los órganos del Estado de no realizar acciones u omisiones que envuelvan una transgresión o desconocimiento de este derecho. Se trata de un deber omisivo o pasivo. Con la segunda, el derecho debe ser amparado, cautelado o tutelado, para evitar que se produzcan vulneraciones. 
Ello incluye hacer cesar conductas invasivas, reparar daños y sancionar a quienes no han respetado dicho derecho. El deber activo de brindar protección le corresponde, principalmente, al Estado y a sus órganos (Corral TalCiani, Hernán; "El respeto y protección de la vida privada en la Constitución de 1980"; en Navarro, Enrique, 20 años de la Constitución chilena 1981-2001, pp. 199-224).

El énfasis con que la Constitución inicia este derecho, es revelador de la especial consideración que le otorga. No todos los derechos consagrados en el artículo 19 utilizan estas expresiones. Ello no obsta a que, cuando entre en fricción con otros derechos, deban ponderarse sus alcances;

Trigésimo Primero: Que la vida privada ha sido definida como 'el conjunto de los asuntos, conductas, documentos, comunicaciones, imágenes o recintos que el titular del bien jurídico protegido no desea que sean conocidos por terceros sin su consentimiento previo' (CEA E., José Luis, Derecho Constitucional Chileno, Tomo II, Ediciones Universidad Católica de Chile, Santiago, 2003, p. 178). También se ha señalado que 'el concepto de 'vida privada' está directamente vinculado a la 'intimidad', a ese ámbito en que el ser humano y la gente de sus afectos conviven, conversan, se aman, planifican el presente y el futuro, comparten alegrias y tristezas, gozan del esparcimiento, incrementan sus virtudes y soportan o superan sus defectos, y fomentan sus potencialidades humanas para su progreso integral, todo ello sin la intervención o presencia de terceros' (Evans de la Cuadra, Enrique, Los Derechos Constitucionales, Tomo I, Editorial Jurídica de Chile, Santiago, 2004, p. 212). Asimismo se ha dicho que vida privada 'es aquella que se ejecuta a vista de pocos, familiar y domésticamente, sin formalidad ni ceremonia alguna, particular y personal de cada individuo, que no es propiedad pública o estatal, sino que pertenece a particulares' (SILVA B., Alejandro, Tratado de Derecho Constitucional, Tomo XI, Editorial Jurídica de Chile, Santiago, 2006, p. 188). 'En ese espacio opaco al que el individuo tiene derecho, hay que precisarlo, caben numerosos aspectos de la vida: ideas y creencias religiosas, la vida sexual y amorosa, vida familiar, estado de salud, comunicaciones escritas u orales, la vida pasada del sujeto, origenes familiares, estado civil y, en general, todo dato, hecho o actividad personal no conocidos por otros, cuyo conocimiento por terceros produzca turbación moral o psíquica al afectado' (Ugarte, José Luis; Derechos, Trabajo y Privacidad; Editorial AbeledoPerrot; Santiago, 2011, p. 75). Para Novoa Monreal, Eduardo (Derecho a la vida privada y libertad de información; Editorial Siglo XXI, 4a edición, México, 1989, p. 49), la vida privada está constituida 'por aquellos fenómenos, comportamientos, datos y situaciones de una persona que normalmente están sustraidos al conocimiento de extraños y cuyo conocimiento por éstos puede turbarla moralmente por afectar su pudor o su recato, a menos que esa misma persona asienta ese conocimiento'.

Cabe precisar, como lo ha hecho esta Magistratura, que la vida privada 'no sólo puede darse en los lugares más recónditos, sino que también se extiende, en algunas circunstancias, a determinados espacios públicos donde se ejecutan especificos actos con la inequivoca voluntad de sustraerlos a la observación ajena' (STC 1894/2011); 
Trigésimo Segundo: Que la importancia de la vida privada está dada por varios factores. En primer lugar, es garantía de autodeterminación individual: 'én un mundo donde toda la actividad de los hombres fuera pública, no cabría la autodeterminación individual. El constitucionalismo, así, exige diferenciar entre las esferas pública y privada y, por tanto, entre lo visible y lo reservado' (DiEz-Picazo, Luis, Sistema de Derechos Fundamentales, Editorial Aranzadi S.A., Navarra, 2008, p. 297). Como lo ha dicho este Tribunal, 'el respeto y protección de la dignidad y de los derechos a la privacidad de la vida y de las comunicaciones, son base esencial del desarrollo libre de la personalidad de cada sujeto, asi como de su manifestación en la comunidad a través de los grupos intermedios autónomos con que se estructura la sociedad' (STC 389/2003).

En segundo lugar, recientemente el Tribunal Constitucional español ha precisado que el derecho a la intimidad se funda en la necesidad de garantizar la existencia de un ámbito propio y reservado frente a la acción y conocimiento de los demás, necesario, según las pautas de nuestra cultura, para mantener una calidad minima de la vida humana, que puede ceder ante la prevalencia de otros derechos, como el derecho a la información cuando se refiere a hechos con relevancia pública, en el sentido de noticiables, y que dicha información sea veraz" (Rol No 4.821/2009, 30 de enero de 2012).

En tercer lugar, se funda en la dignidad personal. Esta Magistratura, en varias sentencias, ha reconocido el valor del derecho a la vida privada. Entre ellas, en el Rol No 389, al señalar que la privacidad, en los variados rubros descritos, integra los derechos personalísimos o del patrimonio moral de cada individuo, los cuales emanan de la dignidad personal, como se ha dicho, y son, por su cualidad de intimos de cada sujeto, los más cercanos o próximos a esta característica, única y distintiva, del ser humano';".

Posteriormente, se hace una referencia a las limitaciones que el derecho a la vida privada tiene, atendiendo a que no es un derecho absoluto, y también a su formulación, especialmente categórica:

"Trigésimo Quinto: Que este Tribunal ha establecido que, dada la protección excepcionalmente categórica que tiene la vida privada (STC 389/2003 y 521/2006) y el que no sea un derecho absoluto (STC 1683/2010, 1800/2011), la regulación del mismo, que lo someta a limitaciones, exige pautas objetivas y sujetas a control que permitan su afectación (STC 389/2003, 433/2005). De ahí que haya rechazado, y considerado inconstitucionales, habilitaciones irrestrictas (STC 389/2003) o sin parámetros objetivos y precisos (STC 1894/2011), facultades absolutamente discrecionales (STC 198/95), potestades que no sean estrictamente indispensables (STC 1365/2009). Sólo ha aceptado restricciones si se afecta el derecho en forma precisa y determinada, la víctima no padezca detrimentos excesivos, y siempre que 
coadyuve a cumplir objetivos del legislador (STC 1365/2009). Así, ha considerado como objetivo legítimo que afecte la vida privada la indemnidad sexual de los menores (STC 1683/2010), la investigación criminal (STC 1939/2011), las remuneraciones de altos gerentes de empresas públicas (STC 1800/2011);

Trigésimo Sexto: Que, en la sentencia Rol No 1.800, esta Magistratura consideró que la vida privada debía ceder ante la publicidad cuando la información solicitada de una persona fuere pública, no sensible (considerando $28^{\circ}$ ). Asimismo, cuando la información afecte intereses legítimos de la comunidad. (Considerandos 270 y $31^{\circ}$ ). Y, finalmente, cuando la información debe ser pública en razón del alto cargo que desempeña la persona afectada y la naturaleza de órgano público de la entidad para la cual labora (considerando 34ㅇ);".

\subsection{Evaluaciones personales son parte de la vida privada}

Finalmente, se concluye que las evaluaciones personales son parte de la vida privada, encontrándose protegidas por dicho derecho fundamental, de acuerdo a los argumentos que a continuación se reproducen:

"Trigésimo Noveno: Que consideramos que las evaluaciones personales se encuentran comprendidas en la vida privada de las personas. En primer lugar, porque así lo establece la ley. Ya señalamos en otra parte de esta sentencia que toda información relativa a los estados de salud, físicos o psíquicos, de las personas, constituye datos sensibles (artículo $2^{\circ}$, letra g, Ley No 19.628). Asimismo, la Ley No 19.882 así lo establece, al señalar que la nómina del concurso es reservada (artículo 50) y que el proceso de selección tiene carácter confidencial, debiendo la Dirección Nacional del Servicio Civil disponer las medidas necesarias para garantizar esta condición (artículo 55).

Enseguida, los tribunales, en reclamos de ilegalidad contra decisiones del Consejo para la Transparencia, donde se discutía la publicidad de estos informes, así también lo han establecido. (Por ejemplo, Roles $\mathrm{N}^{\circ}$ s. 7.938/2010; 436/2010; 3.436/2010, todos de la Corte de Apelaciones de Santiago).

A continuación, el propio Consejo para la Transparencia, hasta antes de la resolución que obligó a la Dirección del Servicio Civil a entregar la información del recurrente, así lo consideraba, tal como se reconoció en estrados por el abogado representante de dicho Consejo;".

De acuerdo a lo anterior, se concluye que las evaluaciones personales, y los antecedentes anexos a ella, son información sensible, que no puede ser difundida libremente, analizándose además, separadamente, los argumentos esgrimidos para la sostener la constitucionalidad de la norma: 
"Cuadragésimo: Que consideramos, por tanto, que la entrega de la evaluación personal y de los documentos anexos a ella vulnera la vida privada del requirente, pues contiene información sensible, que no puede ser conocida por terceros ni difundirse.

En nada obsta a lo anterior el que para fundar la constitucionalidad de la norma impugnada se haya sostenido en estrados que no se afecta la vida privada, porque la publicidad que manda el artículo $8^{\circ}$ es base de la institucionalidad.

$\mathrm{Al}$ respecto, cabe señalar que si bien el artículo $8^{\circ}$ constitucional se encuentra inserto en las bases de la institucionalidad, éste está estructuralmente limitado por el secreto o la reserva, el que procede, entre otras razones que debe tener en cuenta el legislador, por afectar derechos de las personas. La publicidad siempre debe armonizarse con esos derechos. Por lo demás, el artículo 19 de la Constitución, que se encuentra en el Capítulo III de la misma, donde se consagra la protección de la vida privada, no por eso tiene menor entidad o valor que las disposiciones contenidas en el Capítulo I. Más todavía si la Constitución garantiza, respecto de la vida privada, su 'respeto y protección';

Cuadragésimo Primero: Que también se sostuvo que los antecedentes psicolaborales fueron base para la decisión de elegir a la persona seleccionada para el cargo de Director del FOSIS. Ello en nada disminuye el deber de respeto y protección de la vida privada. Más si una ley, con el quórum que exige la Constitución, establece el carácter reservado de la nómina de los seleccionados, de sus antecedentes profesionales y laborales, así como la evaluación de los mismos (artículo 50, Ley No 19.882), y que el proceso de selección tiene el carácter de confidencial (artículo 55, Ley No 19.882);

Cuadragésimo Segundo: Que, además, se sostuvo que la evaluación personal estaba vinculada con la función que se iba a desempeñar, no con la vida privada. Al respecto, debemos considerar, por de pronto, que la vida privada no se pierde por el hecho de postular a un cargo público. Los funcionarios, al igual que todas las personas, tienen aquellos derechos que su relación estatutaria, definida por el legislador, no haya limitado expresa e inequívocamente. Los funcionarios no son personas de segunda categoría ante la Constitución.

También debe tenerse en cuenta que la evaluación personal, de llegar a entregarse, se transfiere sin condiciones de uso o restricciones a su empleo (artículo 19, Ley No 20.285). Por lo mismo, puede llegar a difundirse por el peticionario de la misma, sin que el afectado pueda hacer mucho. Ello puede afectar el control de datos que también es parte de la vida privada;".

Finalmente, la sentencia se refiere al papel que le cabe al Consejo para la Transparencia, respecto de aquellos casos en que el legislador expresamente ha establecido la reserva de determinada información: 
"Cuadragésimo Quinto: Que, finalmente, hay que considerar que esta Magistratura ha objetado que el legislador, sin pautas objetivas, mediante habilitaciones irrestrictas, permita la vulneración de la vida privada.

El punto se torna relevante, porque en el presente caso el legislador, directamente, tanto por aplicación de la Ley No 19.882, como de la Ley No 19.628, ha calificado ciertos antecedentes como secretos o reservados. En ese caso, no caben interpretaciones administrativas. Si bien el Consejo para la Transparencia puede arbitrar conflictos entre las normas sobre acceso a la información pública y la protección de la vida privada (STC 1800/2011), debe hacerlo dentro de los límites que la Constitución y el ordenamiento jurídico establecen, sin que detente poderes omnímodos o ilimitados (STC 1892/2011). Entre estos límites a la publicidad, está la afectación de los derechos de las personas (artículo $8^{\circ} \mathrm{de}$ la Constitución).

Ya señalamos que el secreto o reserva puede ser establecido directa e inmediatamente por el legislador, o recurriendo a una calificación de la autoridad, revisable por dicho Consejo.

Por lo mismo, las leyes de quórum calificado que contemplan ciertos espacios de confidencialidad, dictadas en conformidad a la regla constitucional citada, no quedan supeditadas en su eficacia a la resolución de dicho consejo administrativo.

En la primera situación se encuentran los artículos 55 de la Ley No 19.882 y 2º letra g), de la Ley No 19.628, en virtud de los cuales se desprende -para lo que interesa en el presente caso- que el contenido de las evaluaciones personales requeridas para optar a los cargos de altos directivos públicos, reviste la calidad de secreto o reservado, hasta tanto otra ley, de quórum calificado, no disponga su apertura o difusión. Eso es, por lo demás, lo que establece el artículo 22, inciso primero, del artículo primero de la Ley No 20.285, al señalar que 'los actos que una ley de quórum calificado declare secretos o reservados mantendrán ese carácter hasta que otra ley deje sin efecto dicha calificación'. En cambio, la calificación administrativa de secreto o reserva dura un plazo de cinco años, prorrogables por una sola vez (artículo 22, inciso segundo, del artículo primero de la Ley No 20.285)".

Por las razones anteriormente expuestas, la sentencia acoge el requerimiento de inaplicabilidad, en el siguiente sentido:

"Cuadragésimo Sexto: Que, conforme a lo señalado, el artículo 50, inciso segundo, y la norma de la letra b) del número 1 del artículo 21 de la Ley No 20.285, sobre Acceso a la Información Pública, en la parte que señala 'sin perjuicio que los fundamentos de aquéllas sean públicos una vez que sean adoptadas', resultan inaplicables, en la gestión pendiente ante la Corte de Apelaciones de Santiago, al afectar la vida privada del recurrente, como consecuencia de que faculta 
al Consejo para la Transparencia para disponer la exhibición de evaluaciones personales, que está amparado por dicho derecho, que esta Magistratura debe respetar y proteger".

\section{CONCLUSIÓN}

La sentencia del Tribunal Constitucional comentada brevemente en este trabajo, contiene una aguda definición de los exactos contenidos del artículo $8^{\circ}$ de la Constitución y del artículo primero de la Ley No 20.285 (Ley de Transparencia), contenidos de normas de principio, derecho implícito de acceso a la información pública, ámbito de configuración legislativa de normas de principios y derechos, y también el ámbito del secreto y reserva, su fuente legal, cuando la injerencia "calificación administrativa" del Consejo para la Transparencia es preceptiva y cuando la ley es directamente la fuente de la reserva o secreto. Para concluir la sentencia hace un balance entre el derecho de acceso a la información y el derecho a la vida privada y la inclusión de la información o datos sensibles de las personas dentro del ámbito de la reserva.

En este mismo orden de ideas, la sentencia introduce una buena dosis de cordura, es un momento jurisprudente de inflexión, en relación a la información pública, configuración legal de derechos, rol del Consejo para la Transparencia, en cuanto ente público de la Administración del Estado, titular de una competencia administrativa y ámbitos de reserva o secreto.

La sentencia es un llamado a la moderación al acusado "activismo" del Consejo para la Transparencia, que en ocasiones encuentra eco en la jurisprudencia de tribunales superiores de justicia, como ocurre con la reciente sentencia de la Corte de Apelaciones de Santiago (2 Sala, Rol No 6.248-2011 de 7 de junio de 2012), que llegó a calificar al Consejo como un tribunal al ejercer una función jurisdiccional según lo prevenido en el artículo 33 letra b) de la Ley de Transparencia, y a su decisión de amparo de sentencia (cons. $9^{\circ}, 10^{\circ}$ y $\left.11^{\circ}\right)$.

En otro orden de ideas, es menester consignar críticamente el empleo del Tribunal Constitucional de la categoría de "derechos implícitos", resabio iusnaturalista de la dogmática de los derechos humanos en relativo desuso por la incomensurable y también iusnaturalista categoría del "bloque constitucional de derechos". Los "derechos implícitos" admitidos por el Tribunal Constitucional en el pasado en controles abstractos como los de la Ley No 20.285 y la Nueva Ley de Prensa, se resisten a fenecer y aparecen de la mano pretoriana de esta Judicatura en controles concretos. 
En suma, el Tribunal Constitucional aparece nuevamente tentado por el "fantasma" o "espectro" del neoconstitucionalismo, matriz ideológica que ya es familiar en nuestra doctrina y jurisprudencia. 